\title{
THE TREATMENT OF FLEXION CONTRACTURE OF THE KNEE IN MYELOMENINGOCELE
}

\author{
E. Abraham, Chicago, United States of America, D. G. R. Verinder \\ and W. J. W. Sharrard, Sheffield, England
}

From the Children's Hospital, Sheffield, and the Department of Orthopaedic Surgery, University of Sheffield

\begin{abstract}
A follow-up study, on average four years after operation, of seventy-six children with myelomeningocele who had surgical treatment for flexion contracture of the knee, is reported. After a single operation sixty-eight knees (55 per cent) had a contracture of less than 20 degrees, which was the main criterion of success. About half of the cases of transplantation of the hamstrings to the femur, division or elongation of the hamstrings, or supracondylar osteotomy had successful results. Transfer of the hamstring tendons to the patella was successful in nine of twelve instances, so giving the lowest rate of failure. Forty-five patients were active walkers at follow-up as compared to eighteen before operation. However, only one of the eleven patients over twelve years of age with a motor level above $T .12$ was an active walker at review. Several conclusions are drawn. A flexion contracture of the hip greater than $\mathbf{3 0}$ degrees should be corrected before operation on the knee. Supracondylar osteotomy as a primary procedure should only be used to correct flexion contracture of the knee secondary to malunited fractures. Faradic stimulation is useful in the evaluation of muscle function before operation. An intelligence quotient below 65 and weakness of the arms are relative contraindications for correction of the deformity of the knee.
\end{abstract}

The surgical treatment of flexion contracture of the knee in spina bifida is based mainly on past experience of cerebral palsy and poliomyelitis. The present study was therefore undertaken against a background of limited information about the results in myelomeningocele in order to evaluate the various surgical techniques available.

The neurological state in the lower limbs in spina bifida differs considerably from that in cerebral palsy or poliomyelitis. A limb in which there is no voluntary muscle activity may, nevertheless, contain innervated muscles due to the presence of islets of functioning cord, which can be shown by the response to electrical stimulation. Such muscles may be capable of causing recurrent deformity, and their assessment is essential in planning surgical treatment. The presence of insensitive skin makes correction by serial plasters or traction hazardous, while hydrocephalus presents a constant threat to a stable neurological state and the practical results of treatment.

The aim of operation is to correct the flexion contracture of the knee by dividing or lengthening tight posterior elements and to maintain correction by weakening the knee flexors and, if appropriate, strengthening the knee extensors. The procedures available include hamstring tendon division or elongation, transplantation of hamstring tendons to the lower end of the femur (Eggers 1952) and transplantation of hamstring tendons to the patella (Clark 1956; Keats and Kambin 1962; Conner 1970). Supracondylar femoral osteotomy can be performed when soft-tissue release is insufficient to correct the deformity, or occasionally as a primary procedure.

\section{MATERIAL}

Seventy-six children with myelomeningocele treated surgically at the Sheffield Children's Hospital for knee flexion contracture between 1965 and 1974 were reviewed retrospectively. Forty-seven patients had both knees operated upon, giving a total of 123 knees. There were thirty-five boys and forty-one girls. In seventy-five the myelomeningocele was thoraco-lumbar and in one it was cervico-thoracic. Sixty children ( 80 per cent) had been treated for hydrocephalus by ventriculo-cardiac or ventriculo-peritoneal shunts. The intelligence quotient on the Wechsler scale was available in seventy of the children, the average being 81 per cent. The youngest child at the time of operation was aged two years and the oldest fourteen (Fig. 1), but two-thirds were operated upon before the age of six. The average follow-up was four years, with a minimum of one year.

The children had been selected for operation if the knee flexion contracture prevented the fitting of a caliper, resulted in pressure sores or hampered gait. A stable neurological condition and satisfactory renal function were prerequisites for operation. Any child showing a desire to walk, as indicated by attempts to climb on furniture, was considered suitable for operation regardless of the level of intelligence.

Dr Edward Abraham, Department of Orthopaedic Surgery, The Abraham Lincoln School of Medicine, University of Illinois, 840 South Wood Street, Chicago, Illinois 60612 , U.S.A.

David G. R. Verinder, F.R.C.S., 160 Crimicar Lane, Sheffield S10 4EJ, England.

W. J. W. Sharrard, M.D., Ch.M., F.R.C.S., 140 Manchester Road, Sheffield S10 5DL, England.

VOL. 59-B, No. 4, NOVEMBER 1977 
Each patient was examined with particular reference to the spine and lower limbs. A chart of voluntary activity was made using the Medical Research Council (1942) scale, and the level of sensory innervation was identified. Percutaneous faradic stimulation was performed to determine the degree of reflex activity in muscles or muscle groups; it was also used to assess the individual function of the medial hamstrings because it was not always possible to differentiate clinically between that of gracilis, sartorius and semitendinosus.

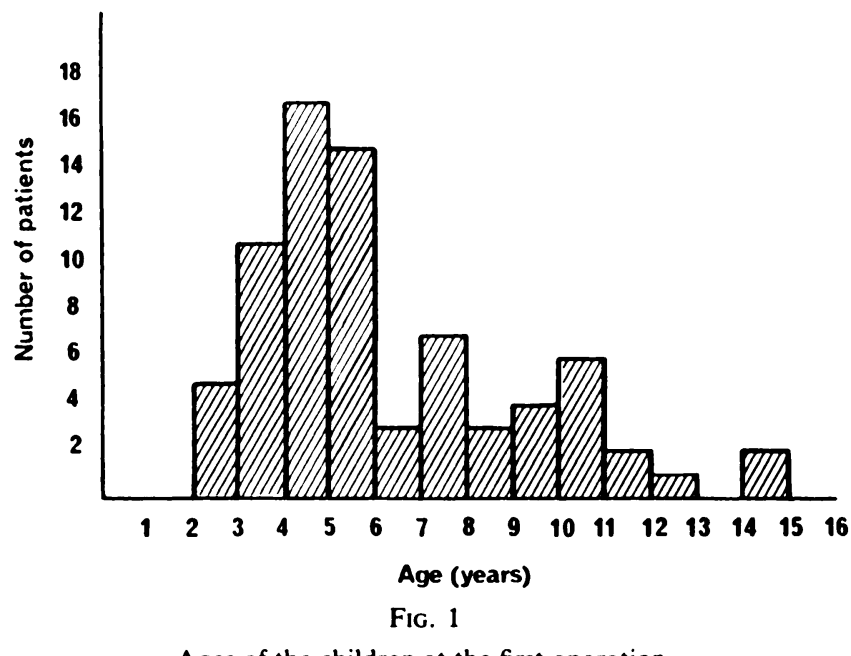

Ages of the children at the first operation.

The level of motor function in each treated limb at the time of review is summarised in Table I.

The flexion contracture before the first operation ranged from 20 to 90 degrees, with an average of 36 degrees (Table II). Five different operations had been performed. Hamstring division and elongation were grouped together because they were frequently combined. Four of the ten children in whom hamstring tendons were transferred to the patella also had supracondylar osteotomy for residual contracture of less than 20 degrees. The level of motor function for these limbs was: above T. 12, six; L.1, one; L. 2 and 3, three; L.4, one; and S.1, one limb. The patients were not selected for this operation. Also, there was no evidence to suggest that any one procedure had been favoured over another for a given level of motor function.

About half of those patients who had received hamstring tendon transfer to the femur, hamstring tendon division or elongation, or supracondylar osteotomy and transfer of the hamstring tendons to the patella had clinical paralysis above the twelfth thoracic nerve root. Patients having supracondylar osteotomy as a primary procedure were on average three years older than patients who had the various other procedures.

\section{TECHNIQUE OF OPERATION}

Any flexion contracture of the hip over 30 degrees was released before operation on the knee. In all the softtissue procedures the hamstring tendons were approached by postero-lateral and postero-medial incisions with the patient prone.

Hamstring release consisted in elongation or division of all the tight tendons preventing extension of the knee. Division of the posterior capsule of the knee, the ilio-tibial band, the anterior retinacular expansions and the origins of the gastrocnemii might be necessary in varying degree. In the most severe cases, division of the cruciate and of the medial and lateral ligaments of the knee was performed; supracondylar osteotomy was then added if more correction was needed. Residual contracture had to be accepted if undue tension threatened the popliteal neurovascular structures.

Supracondylar osteotomy was performed by removing a wedge based anteriorly and closing it by extension of the knee, using the intact posterior cortex as a hinge. Any varus or valgus deformity was corrected by modifying the wedge. Internal fixation was not usually required.

Transfer of the semitendinosus and biceps femoris tendons to the patella was performed through long postero-medial and postero-lateral incisions with the patient supine. The gracilis was also sometimes used to strengthen the transfer. Any tight posterior structures were of course released. Through a transverse incision at the upper border of the patella, a transverse hole was made in the substance of the bone through which the tendon or tendons were passed and attached to the quadriceps expansion. If their length was insufficient to allow them to be passed through the patella, firm fixation could usually be obtained at the supramedial and supralateral borders of the bone.

The limb was immobilised in a well-padded plaster, for three to four weeks after hamstring tendon elonga-

TABLE I

Neurological Detall.s

\begin{tabular}{|c|c|}
\hline $\begin{array}{c}\text { Lowest functioning } \\
\text { motor root }\end{array}$ & Number of limbs \\
\hline Above T.12 & 62 (50 per cent) \\
T.12 and L.1 & 15 (12 per cent) \\
L. 2 and L.3 & 17 (14 per cent) \\
L.4 and L.5 & 23 (19 per cent) \\
S.1 and S.2 & 6 (5 per cent) \\
\hline
\end{tabular}

TABLE II

Detalls of the Procedures

\begin{tabular}{|c|c|c|}
\hline Procedure & $\begin{array}{l}\text { Number } \\
\text { of knees }\end{array}$ & $\begin{array}{c}\text { Average } \\
\text { contracture } \\
\text { (degrees) }\end{array}$ \\
\hline Hamstring tendons to femur & 38 & 36 \\
\hline Hamstring tendons- division or elongation & 32 & 34 \\
\hline Supracondylar osteotomy & 30 & 33 \\
\hline Hamstring tendons to patella & 12 & 40 \\
\hline Hamstring tendon division and osteotomy & 11 & 46 \\
\hline Total & 123 & \\
\hline
\end{tabular}

THE JOURNAL OF BONE AND JOINT SURGERY 
tion and division and for six weeks after transfer procedures or after supracondylar osteotomy.

Complications-Fourteen limbs fractured after immobilisation was discontinued, twelve femora and two tibiae; all were treated successfully by simple splintage with layered crêpe and wool bandage. There were four deep wound infections, three with sloughing of the skin, but all healed soundly. Displacement of the supracondylar osteotomy occurred in two cases. This was treated by inserting a Steinmann pin through the proximal fragment and through the tibia and then applying a plaster cast. Union occurred satisfactorily but with some shortening of the limbs.

\section{RESULTS}

The main criterion of a successful operation was a flexion contracture of less than 20 degrees at follow-up. A successful walker was defined as one who could walk at least 25 metres with or without the aid of calipers and other supporting devices; an improved patient was one who started as a sitter and ended as a stander capable of walking less than 25 metres; and a failure was one who had a contracture greater than 20 degrees or who was still a sitter.

TABLE III

Distribution of Successful. Results

\begin{tabular}{|c|c|c|}
\hline Procedure & $\begin{array}{l}\text { After first } \\
\text { operation }\end{array}$ & $\begin{array}{l}\text { After repeated } \\
\text { operation(s) } \\
\text { (22 knees) }\end{array}$ \\
\hline Hamstring tendons to femur & $19(50$ per cent $)$ & +6 (66 per cent) \\
\hline $\begin{array}{l}\text { Hamstring tendons-division } \\
\text { or elongation }\end{array}$ & 17 (53 per cent) & $+2(59$ per cent $)$ \\
\hline Supracondylar osteotomy & $16(53$ per cent $)$ & +4 (67 per cent) \\
\hline Hamstring tendons to patella & 9 (75 per cent) & None \\
\hline $\begin{array}{l}\text { Hamstring tendon division } \\
\text { with osteotomy }\end{array}$ & 7 (64 per cent) & $+1(73$ per cent $)$ \\
\hline Totals & $68(55$ per cent $)$ & 81 (66 per cent) \\
\hline
\end{tabular}

\section{Flexion contracture of the knee}

Sixty-eight knees ( 55 per cent) had a contracture of less than 20 degrees after the first operation (Table III). There was a remarkable similarity in the results obtained with supracondylar osteotomy alone, hamstring tendon elongation and division, and hamstring tendon transplantation to the femur, each being about 50 per cent successful. Twenty-two of the fifty-five knees not successfully treated by the first operation were operated upon again, with success in thirteen. The overall success rate was therefore 66 per cent. Hamstring tendon division with osteotomy gave 64 per cent success.

The best results were obtained with transplantation of the hamstring tendons to the patella (Figs. 2 and 3):

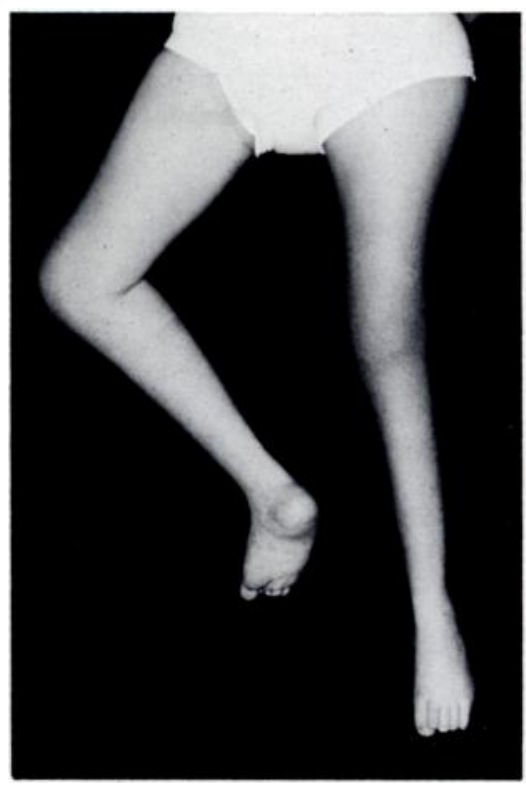

Fig. 2

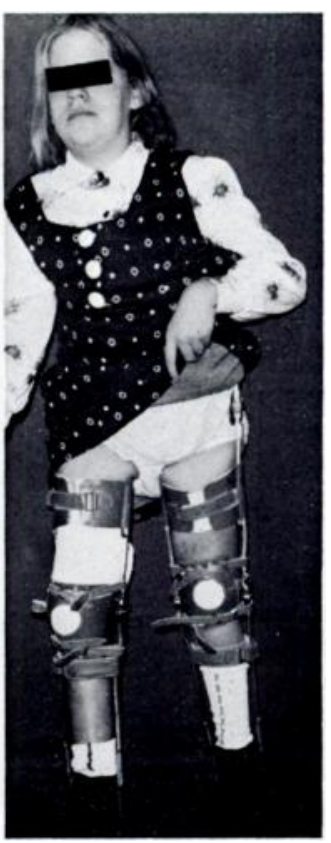

Fig. 3
Figure 2-Before operation, showing the lower limbs of a girl aged twelve with 30 degrees of fixed flexion of the knee causing inability to walk, which was treated by transplantation of semitendinosus and biceps femoris to the patella and an extensive soft-tissue release. Figure 3-The same patient as in Figure 2 six weeks after operation and now able to walk.

nine out of twelve were successful. The number of cases, however, was insufficient to show a statistically high difference between all the procedures.

The three unsuccessful results occurred in two patients. One with bilateral procedures had a motor level at T.10 with abduction and lateral rotation deformities of the hips; this patient never walked. The other patient had a motor level at L.3 and an I.Q. of 104; despite a contracture of 30 degrees she wore her caliper eight hours daily with some difficulty.

The role of flexion contracture of the hip as a contributory factor in flexion deformity of the knee was analysed. Of the fifty-five failures, twenty cases ( 36 per cent) had a flexion contracture of the hip greater than 30 degrees. With regard to twenty-eight hips with flexion contracture of more than $\mathbf{3 0}$ degrees before the operation on the knee, correction failed in twenty ( 71 per cent) of the corresponding knees.

The level of motor nerve root function significantly influenced the outcome (Table IV). A successful correction was obtained in only 42 per cent of completely paralysed limbs. In partially paralysed limbs the results improved with lower levels of paralysis.

Only in four of the fifty-five limbs with flexion contracture of the knee greater than 20 degrees was adduction of the hip joint less than 20 degrees. Before operation significant contracture of the ilio-tibial band was noted clinically in those patients who had a combination of abduction, flexion and lateral rotation deformity of the hip. Release of the distal ilio-tibial 
TABLE IV

The Influence of the Level of Paralysis

\begin{tabular}{|c|c|c|c|c|}
\hline $\begin{array}{c}\text { Lowest } \\
\text { functioning } \\
\text { motor root }\end{array}$ & $\begin{array}{c}\text { Number } \\
\text { of } \\
\text { limbs }\end{array}$ & $\begin{array}{c}\text { Flexion } \\
\text { contracture less } \\
\text { than } 20 \text { degrees }\end{array}$ & $\begin{array}{c}\begin{array}{c}\text { Number } \\
\text { of } \\
\text { patients }\end{array} \\
\text { pon }\end{array}$ & $\begin{array}{l}\text { Number of } \\
\text { successful } \\
\text { walkers }\end{array}$ \\
\hline Above T.12 & 62 & $\begin{array}{c}26 \\
\text { (42 per cent) }\end{array}$ & 35 & $\begin{array}{c}11 \\
\text { (31 per cent })\end{array}$ \\
\hline T.12 and L. 1 & 15 & $\begin{array}{c}6 \\
\text { (40 per cent) }\end{array}$ & 10 & $\begin{array}{c}6 \\
\text { (60 per cent })\end{array}$ \\
\hline L. 2 and L. 3 & 17 & $\begin{array}{c}10 \\
(59 \text { per cent })\end{array}$ & 10 & $\begin{array}{c}10 \\
(100 \text { per cent })\end{array}$ \\
\hline L. 4 and L. 5 & 23 & $\begin{array}{c}20 \\
\text { (87 per cent) }\end{array}$ & 17 & $\begin{array}{c}13 \\
\text { (76 per cent) }\end{array}$ \\
\hline S.1 and S.2 & 6 & $\begin{array}{c}6 \\
\text { (100 per cent) }\end{array}$ & 4 & $\begin{array}{c}4 \\
(100 \text { per cent })\end{array}$ \\
\hline
\end{tabular}

band was therefore done routinely at the time of operation for longstanding flexion contracture of the knee.

Fracture of the femur or tibia after operation did not seem to affect the outcome of the procedure; only two of fourteen patients in whom this occurred had a poor result.

\section{Ability to walk}

The ability of a patient with myelomeningocele to walk is dependent on so many factors-level of motor innervation; presence of hydrocephalus; intelligence; upper limb weakness; deformity of the spine, hip, knee or foat - that it is almost impossible to isolate the effect of operations upon the knee on the ultimate result. All but six patients had needed operative treatment to other parts of the lower limb or spine. In this series (Table V), thirty-eight patients ( 50 per cent) were sitters before

TABLE V

The Effect of the Operations on the Abil.tty to Walk

\begin{tabular}{|l|l|r|r|}
\hline Status & Before operation & \multicolumn{1}{|c|}{$\begin{array}{c}\text { After first } \\
\text { operation }\end{array}$} & $\begin{array}{c}\text { After repeated } \\
\text { operation(s) } \\
\text { (15 patients) }\end{array}$ \\
\hline Sitter & $38(50$ per cent $)$ & $21(28$ per cent $)$ & $23(30$ per cent $)$ \\
Stander & $20(26$ per cent $)$ & $9(12$ per cent $)$ & $8(11$ per cent $)$ \\
Walker & $18(24$ per cent $)$ & $46(60$ per cent $)$ & $45(59$ per cent $)$ \\
\hline
\end{tabular}

operation, and at follow-up twenty-three ( 30 per cent) were still so. Eighteen patients ( 24 per cent) were competent walkers before the operation and this figure rose to forty-five (59 per cent) at follow-up. Whatever procedure was employed, the main factor in successful walking when deformity had been corrected was the level of voluntary motor activity.

An additional analysis was made of eighteen patients who were over the age of twelve at follow-up, which averaged seven and a half years. Eight were sitters before the operation, but at follow-up this figure had increased to eleven. Only one of the eleven patients with a functioning motor level above T.12 was still actively walking. This finding confirms the overall impression of the severely paralysed myelomeningocele patients that although an operation in childhood may give limited walking ability with appliances, they are later unable to maintain this as they reach adolescence (Hoffer et al. 1973). In contrast, six out of seven patients with innervation down to L. 3 or below were still walking actively with or without appliances at the time of followup.

\section{Secondary correction of recurrent deformity}

Twenty-two knees in fifteen patients were subjected to further operation for recurrent deformity, the most common secondary operation being supracondylar osteotomy. This was performed sixteen times in fourteen limbs but with success in only three. Transplantation of the hamstring tendons to the patella or to the femur, usually combined with a supracondylar osteotomy, was performed in five cases with four successes.

Conspicuous failure in spite of repeated procedures was found in six patients in whom there was a specific combination of deformities which included lateral rotation-abduction deformity of the hip, severe flexion deformity of the knee, equinus, and flexion deformity of the toes (Fig. 4). Motor assessment revealed reflex activity confined to the sacral segments. Flexion deformity recurred in all patients, including one in whom no less than four operations had been performed on one limb.

There were fifteen knees in ten patients where maximum passive knee flexion was less than $\mathbf{9 0}$ degrees. Ten of the limbs had no voluntary activity; the remaining four had motor root innervation ranging from L. 1 to L.4.

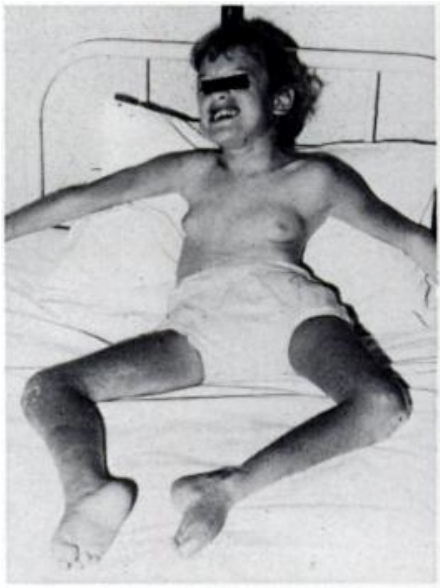

Fig. 4

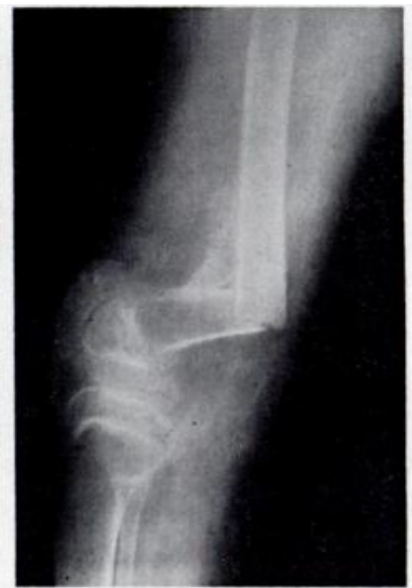

Fig. 5
Figure 4-To illustrate a conspicuous failure. This girl of nine with a 45-degree contracture of the right knee had had a modified Eggers procedure five years previously. The motor level was above the twelfth nerve root. The flexed toes suggested reflex activity in the sacral segments, which was confirmed by open faradic stimulation and muscle biopsy. Figure 5-A lateral radiograph showing union of a 90-degree supracondylar osteotomy. The knee, however, could now flex only to 50 degrees. 
One patient with only 5 degrees of flexion movement had an operation to correct 80 degrees of contracture but the knee required prolonged immobilisation for a wound infection. The opposite knee flexed to 120 degrees. She was a sound walker and had no difficulty with sitting.

Two patients had maximum knee flexion to 45 degrees. One of these patients had a maximum flexion of 10 degrees in the non-operated knee. Her motor root innervation was L.4, whereas the other patient had an L. 1 motor level. Both children were six years old and they were having increasing difficulty with sitting and getting in and out of confined areas. They were both sound walkers.

In one patient, both knees flexed to only 20 degrees. His motor level was above T.12 innervation and his I.Q. was 62 . He had a severe kyphosis and he was unable to sit up independently.

Six patients with ten operated knees having maximum flexion between 65 and 85 degrees had no apparent sitting difficulties and all but one were sound walkers.

Six of these knees with limited flexion had supracondylar osteotomies (Fig. 5), and two were associated with hamstring tendon transplants to the patella and two with hamstring division. Six knees had only hamstring division or elongation and two had modified Eggers procedures. One patient had the hamstring tendons transferred to the patella.

\section{DISCUSSION}

The management of flexion deformity of the knee and the results of operation both proved much less satisfactory in myelomeningocele than in poliomyelitis or cerebral palsy. Flexion deformity of a limb flail from poliomyelitis can almost always be corrected by a combination of conservative and operative treatment, usually with assured maintenance of correction. Flexion deformity of the knee in cerebral palsy shares the common findings with deformity in myelomeningocele in that flexion deformity of the hip predisposes to the development of knee flexion deformity, and that if both are present the hip flexion deformity must be corrected before that of the knee (Figs. 6 and 7).

The finding that correction was more satisfactory in the presence of more intact innervation did not come as a surprise. The better the innervation of the quadriceps, the more likely it is that any operative procedure that corrects flexion deformity and weakens knee flexion activity will succeed. By contrast, when there is only reflex activity in the sacral segments any attempt to correct knee deformity and to maintain it corrected by procedures upon the knee itself is doomed to failure. A high proportion of limbs with flexion deformity of the knee fall between these two extremes.

In this series the success rate for operative treatment in general was about 50 per cent. This finding

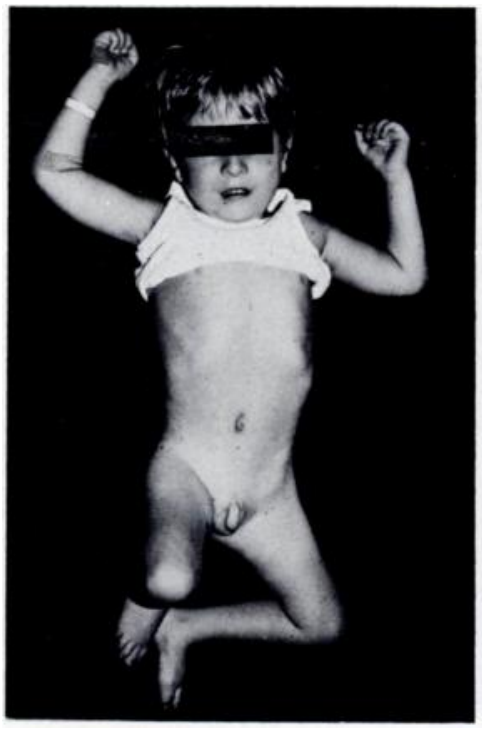

Fig. 6

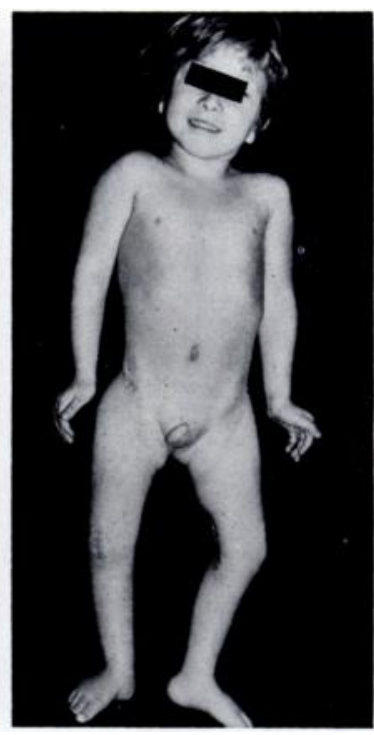

Fig. 7
Figure 6-A boy aged five before operation, with a motor level above T.12. There is marked contracture of the right hip and of both knees. Figure 7-The same child after two operations: first, release of the flexion contracture of the hip, and six weeks later, bilateral transplantation of semitendinosus and biceps to the patella.

suggests that consideration of operative correction in a case of severe clinical paralysis should be tempered by an appreciation of the likely result and the future walking function. In a child below the age of seven, one attempt at correction of the deformity is justifiable in the hope of maintaining ability to walk with apparatus for a few more years while accepting the almost inevitable result of a wheelchair existence. If flexion deformity recurs after one correction in early childhood, a further correction with transplantation of hamstring muscles to the patella may be considered if that has not already been done.

The analysis did not reveal a highly significant advantage of one operative procedure over another, though the figures suggest that transfer of the hamstring tendons to the patella is the most effective, and that supracondylar osteotomy alone is the most unsatisfactory. Correction by osteotomy is not maintained if there is any unbalanced spontaneous activity in the hamstring muscles. Remoulding occurs rapidly and undesirable secondary changes in the articular surfaces of the femur develop with limitation of knee flexion. In our view supracondylar osteotomy should only be done to correct either the last few degrees of flexion deformity when a soft-tissue operation has failed to achieve full extension, or for valgus or varus deformity, or for deformity secondary to a malunited fracture. Hamstring division or elongation, or transfer of the hamstrings to the lower end of the femur, appeared to be successful only when the power of the quadriceps muscle was at least grade 3 before operation. In patients with the quadriceps muscle paralysed, transfer of the hamstring tendons to the patella seemed to give the best results, and the fact that this transplant could function was 
demonstrated by the discovery of weak extension of the knee on electrical stimulation.

The limb most difficult to treat is one in which there is little or no evidence of voluntary activity in any of the knee muscles yet which has developed a flexion deformity. If the hamstrings are found to respond strongly to electrical stimulation, transfer should be made to the patella to try to prevent recurrent flexion deformity.

The benefits of corrective treatment of the knee can only be realised in patients who have the potential to walk with extensive caliperage. Patients with severe hydrocephalus, or with an intelligence quotient of less than 65 , or with upper limb weakness or spasticity, will not be able to do so, and in them knee flexion deformity can be left uncorrected unless there is a danger of pressure of the heels against a wheelchair. Similar considerations apply to children over the age of twelve who have opted for a wheelchair existence and who have flexion deformities of both hips and knees. A child of six or seven who has already managed to walk but has ceased to do so because of knee flexion deformity, or one who shows a desire to walk but is unable to do so for the same reason, should be given the benefit of operative correction. He may then maintain enough walking activity to minimise osteoporosis and trophic changes in the lower limbs and to avoid the excessive obesity and ischial ulceration that may result from prolonged sitting.

\section{REFERENCES}

Clark, J. M. P. (1956) Muscle and tendon transposition in poliomyelitis. In Modern Trends in Orthopaedics (second series), pp. 116-143. Edited by $\mathrm{H}$. Platt. London: Butterworth.

Conner, A. N. (1970) The treatment of knee flexion contractures in poliomyelitis. Journal of Bone and Joint Surgery, 52-B, 138-144.

Eggers, G. W. N. (1952) Transplantation of the hamstring tendons to femoral condyles in order to improve hip extension and to decrease knee flexion in cerebral spastic paralysis. Journal of Bone and Joint Surgery, 34-A, 827-830.

Hoffer, M. M., Feiwell, E., Perry, R., Perry, J., and Bonnett, C. (1973) Functional ambulation in patients with myelomeningocele. Journal of Bone and Joint Surgery, 55-A, $137-148$.

Keats, S., and Kambin, P. (1962) An evaluation of surgery for the correction of knee-flexion contracture in children with cerebral spastic paralysis. Journal of Bone and Joint Surgery, 44-A, 1146-1154.

Medical Research Council (1942) Aids to the Investigation of Peripheral Nerve Injuries. War Memorandum No. 7. London: H.M.S.O. 